九州大学学術情報リポジトリ

Kyushu University Institutional Repository

\title{
Behavior Simulation of Tractor Driven on Slopes and Undulating Roads.
}

CHOE, Jung Seob

Department of Precision Mechanical Engineering, Kyungpook National University

AKIMUNE, Hiromasa

Graduate School of Bioresource and Bioenvironmental Sciences, Kyushu University

SHIN, Soyoung

Graduate School of Bioresource and Bioenvironmental Sciences, Kyushu University

INOUE, Ei ji

Laboratory of Agricultural Machinery and Production Systems Design, Division of Bioproduction Environmental Sciences, Department of Agro-environmental Sciences, Faculty of Agriculture, Kyushu University

他

https://doi.org/10.5109/2232308

出版情報：九州大学大学院農学研究院紀要. 64 (1)，pp. 157-162，2019-02-28. Faculty of Agriculture, Kyushu University

バージョン :

権利関係 : 


\title{
Behavior Simulation of Tractor Driven on Slopes and Undulating Roads.
}

\section{Jung Seob CHOE ${ }^{1}$, Hiromasa AKIMUNE², Soyoung SHIN ${ }^{2}$, Eiji INOUE, Muneshi MITUSOKA*, Takashi OKAYASU and Yasumaru HIRAI}

\author{
Laboratory of Agricultural Machinery and Production Systems Design, Division of Bioproduction \\ Environmental Sciences, Department of Agro-environmental Sciences, Faculty of Agriculture, \\ Kyushu University, Fukuoka 819-0395, Japan \\ (Received October 31, 2018 and accepted November 12, 2018)
}

\begin{abstract}
In this study, we have developed a behavior simulation program for tractors by using a Runge-Kutta method on the existing fixed support model and front-wheel pivot model, and through a comparative analysis, we examined the difference between the models and their usefulness. And the summary of the results is as follows.

1. As for front wheel reaction force, the fixed support model showed changes involving left-right symmetry whereas the front-wheel pivot model, as a whole, showed changes in fluctuation according to the motion of the machine.

2. As for rear wheel reaction force, the fixed support model showed changes involving left-right symmetry as with the front wheels whereas it showed in nearly equal levels at both left and right wheels for the front-wheel pivot model, thus verifying that the front-wheel pivot mechanism exercises huge influence not only on the dynamic characteristics of the front axle but also on those of the rear axle.

3. The rolling angle for the fixed support model was greatly influenced by changes in four-wheel reaction force, whereas the front-wheel pivot model did not show any changes when the front wheels were climbing the bump.
\end{abstract}

Key words: tractor, behavior simulation, front-wheel pivot, reaction force, rolling angle

\section{INTRODUCTION}

Lately, aging operators are looming as a big issue for the South Korean and Japanese agriculture. According to a survey by the Japanese Ministry of Agriculture, Forestry and Fisheries, the ratio of those who are 65 or older among those working in agriculture exceeded $60 \%$ in 2017, thus attesting to faster aging of workers in comparison to other industries. However, the farm land per farming household increased from 1.96 ha in 2010 to 2.41 ha in 2017, because the number of farmers decreased and therefore farm land managed by each household naturally increased. Looking ahead, provided that there will be no new young recruits in the sector, we expect that within the next two decades, Japanese agriculture will suffer a severe labor force shortage and the South Korean counterpart will be no different. Accordingly, agriculture is considered as the sector where automation and robotization should be adopted more urgently, in comparison to other industries. However, as most of the agricultural robots that have been researched and developed are targeted for widearea operations in the plain fields, a large number of the small-sized farming households in the middle-level mountainous regions will inevitably need the existing types of farm machines operated by people. Therefore,

Department of Precision Mechanical Engineering, Kyungpook National University, Korea

${ }^{2}$ Graduate School of Bioresource and Bioenvironmental Sciences, Kyushu University, Japan

* Corresponding author (E-mail: mitsuoka@bpes.kyushu-u. ac.jp) high functionality and intelligence will necessarily be crucial in supporting the future agricultural production.

As agricultural operations thus become highly efficient, there is a growing call for reducing accidents causing death during agricultural work, which is more frequent compared to other industries. According to a report from the Japanese Ministry of Agriculture, Forestry and Fisheries, Japan had 338 deaths during farm work in 2015, a number about 9 times the average number of accidents causing death per 100,000 employees in the other industries or about 2 times the average number of accidents in the construction industry, an industry that involves dangerous work. Therefore, there is an urgent need to come up with a plan to reduce the number of accidents in the agricultural industry. Especially, there were 284 reported deaths among those who were 65 years of age or older, and this was about $84 \%$ of the total deaths. Also, deaths during operating machinery was about $60 \%$ of the total deaths. Moreover, about $70 \%$ of the deaths that occurred during operation of machinery was caused by rollover or falls, while traveling on the narrow ridge of rice field or slopes. Tractors were involved in 108 deaths, registering the biggest part (approximately 30\%) of all the deaths caused by operating different machines. Unlike automobiles that travel on paved roads, farm machines frequently operate on narrow ridges of rice fields or severely bumpy road surfaces and register a higher center of gravity, which is the main cause for rollovers and falls. These days, Japan wages safety awareness campaigns prior to the start of the spring and fall farm work seasons to reduce farming accidents, which has yet to significantly reduce rollovers and falls. 
Due to the recent progress in the development of small and high-precision sensors, there is brisk R\&D work underway on external data acquisition that taps into cameras as well as infrared and ultrasound sensors now available in the market. In the automotive sector, research to increase safety using sensors for automated driving and collision prevention technology has been implemented and much of it has found actual applications. Safety required for automobiles is mostly intended to prevent collisions with pedestrians or among vehicles, whereas safety for agricultural vehicles is mainly focused on preventing the machines from rolling over or falling while traveling on poor road conditions. In order to prevent rollover or falling of farm machinery that are operated on poor road conditions with other external disturbance factors, we need to acquire data on the condition of the road and predict safety and danger hazard factors of the machine. If we can obtain information on slopes or roads with poor surface conditions where rollovers or falls frequently occur, and if we could estimate the safety and behavior of the machine using such information, it could be useful in the operation of the machinery, by identifying dangerous locations, cautioning the operator, or automated operation of the machinery in mountainous areas. Moreover, the abovementioned technology is required to realize a rollover avoidance system that works by controlling driving speed or steering angle when detecting hazards.

In their research report on the prevention of rollovers and falls of farming machines, especially tractors, Aoyanagi et al. (2016) created an equation for the updown, pitching, rolling, and forward and backward motions of tractors that travel on slopes and simulated tractor behavior on the slopes where rollovers and falls actually occurred. Also, Li et al. (2015) created the dynamic model for a tractor that adopted front-wheel pivot mechanism and interpreted its behavior.

This study, which is designed to develop a system that can predict a machine's hazards and thereby prevent accidents by acquiring slope and poor road surface driving data and combining it with the machine's behaviors, has examined the differences and usefulness of the existing fixed support model and the front-wheel pivot model by developing a simulation program for tractors that travel on slopes and bumpy road surfaces, using the Runge-Kutta method, and making a comparative analysis of its results.

We expect that the usefulness of this simulation program can be more solidly established in a further study by making a comparative analysis on the actual dynamic behaviors of the tractor and this simulation result.

\section{MATERIALS AND METHOD}

\section{Tractor Behavior Model}

The behaviors of a tractor that operates on slopes can be expressed with 4 degree of freedom (DOF) including up-down, pitching, rolling, and forward-backward directions. By adding this to the equation of motion that considers the front-wheel swing mechanism, we can express the behaviors of a tractor with the frontwheel swing mechanism. The tractor's behavior can be identified with the reaction force on each wheel and the displacements in up-down direction, pitching and rolling angles, and the equations of motion in the forward-backward direction are necessary to figure out the driving force needed for traveling on a slope. The tractor modeling was performed under the assumptions below.

- The tractor tire is modeled as a spring-damper unit.

- The machine except the tires constitutes a rigid body.

- A yawing motion does not occur.

- Slips do not occur.

- There are only points of contact between the tire and the road surface.

The behavior model of a tractor that operates on a slope is shown in Fig. 1. Equations of motions for 4 DOFs, including machine's up-down, pitching, rolling, and forward-backward DOFs, can be derived from this model. Fig. 2 indicates the model for the front-wheel swing mechanism of the tractor. The equations of motions for the up-down, pitching, rolling, and forwardbackward motions at the machine's center of gravity that does not take into account the machine pivot (Aoyanagi et al., 2016) is shown in the equations (1) to (5), and the equations of motions for the front-wheel pivot mechanism are shown in equations (6) to (7), while the equation of motions for the machine's center of gravity that takes into account the front-wheel pivot mechanism is presented in equations (8) to (11), and the reaction force sustained by the wheels is expressed in equation (12).

$$
\begin{aligned}
& M \ddot{z}=M g-F \cos \phi \cos \theta+\mu F \sin \phi \cos \theta-D \sin \phi \\
& I_{\mathrm{y}} \ddot{\phi}=\left(R_{\mathrm{fr}}+R_{\mathrm{rr}}\right) L_{\mathrm{f}}-\left(R_{\mathrm{rr}}+R_{\mathrm{rl}}\right) L_{\mathrm{r}}-\mu F \cos \theta L_{\mathrm{g}} \\
& I_{\mathrm{x}} \ddot{\theta}=\left(R_{\mathrm{fr}}+R_{\mathrm{rr}}\right) B_{\mathrm{r}}-\left(R_{\mathrm{fl}}+R_{\mathrm{rl}}\right) B_{1}-\gamma F \cos \phi L_{\mathrm{g}} \\
& M \ddot{x}=D \cos \phi-\mu F \cos \theta \cos \phi-F \cos \phi \sin \phi \\
& F=R_{\mathrm{fr}}+R_{\mathrm{fl}}+R_{\mathrm{rr}}+R_{\mathrm{rl}} \\
& I_{\mathrm{fx}} \ddot{\theta}=R_{\mathrm{fr}} B_{\mathrm{fr}}-R_{\mathrm{fl}} B_{\mathrm{fl}}-\gamma\left(R_{\mathrm{fr}}+R_{\mathrm{fl}}\right) \cos \phi L_{\mathrm{g}} \\
& F_{\mathrm{f}}=R_{\mathrm{fr}}+R_{\mathrm{fl}} \\
& M \ddot{z}=M g-F \cos \phi \cos \theta+\mu F-D \sin \phi \\
& I_{y} \ddot{\phi}=\left(F_{\mathrm{f}} L_{\mathrm{f}}-\left(R_{\mathrm{rr}}+R_{\mathrm{rl}}\right) L_{\mathrm{r}}\right)-\mu F \cos \theta L_{\mathrm{g}} \\
& I_{\mathrm{x}} \ddot{\theta}=\left(R_{\mathrm{rr}} B_{\mathrm{fr}}-R_{\mathrm{rl}} B_{\mathrm{fl}}\right)-\gamma F \cos \phi L_{\mathrm{g}} \\
& M \ddot{x}=D \cos \phi-\mu F \cos \theta \cos \phi-F \cos \phi \sin \phi \\
& R=(z+L \phi+B \theta) k+(\dot{z}+L \dot{\phi}+B \dot{\theta}) c
\end{aligned}
$$

The symbols in these equations indicate the following.

$G$ : Machine's center of gravity

$x$ : The displacement of the machine in the forwardbackward directions (m)

$y$ : The displacement of the machine in the left-right directions (m)

$z$ : The displacement of the machine in the up-down directions (m)

$\phi$ : The machine's pitching angle (rad)

$\theta$ : The machine's rolling angle (rad)

$L_{\mathrm{g}}$ : The length from the ground to the tractor's center of gravity (m)

$L_{\mathrm{f}}$ : The length from the tractor's center of gravity to the front wheels in the traveling direction (m)

$L_{\mathrm{r}}$ : The length from the tractor's center of gravity to 
the rear wheels in the traveling direction (m)

$B_{\mathrm{fl}}$ : The length from the tractor's center of gravity to the left front wheel in the lateral direction (m)

$B_{\mathrm{fr}}$ : The length from the tractor's center of gravity to the right front wheel in the lateral direction (m)

$B_{\mathrm{rl}}$ : The length from the tractor's center of gravity to the left rear wheel in the lateral direction (m)

$B_{\mathrm{rr}}$ : The length from the tractor's center of gravity to the right rear wheel in the lateral direction (m)

$R_{\mathrm{fl}}$ : Ground reaction force to the left front wheel (N)

$R_{\mathrm{fr}}$ : Ground reaction force to the right front wheel (N)

$R_{\mathrm{rl}}$ : Ground reaction force to the left rear wheel (N)

$R_{\mathrm{rr}}$ : Ground reaction force to the right rear wheel (N)

$F_{\mathrm{f}}$ : The net ground reaction forces to the right front wheel and the left front wheel $(\mathrm{N})$

$\mu$ : The coefficient of friction in the forward-backward directions

$\gamma$ : The coefficient of friction in the left-right directions

$M$ : The mass of the tractor body $(\mathrm{kg})$

$g$ : Gravitational acceleration $\left(\mathrm{m} / \mathrm{s}^{2}\right)$

$D$ : Tractor's thrust $(\mathrm{N})$

$I_{\mathrm{x}}$ : The moment of inertia in the tractor body's rolling direction $\left(\mathrm{kg} \cdot \mathrm{m}^{2}\right)$

$I_{\mathrm{y}}$ : The moment of inertia in the tractor body's pitching direction $\left(\mathrm{kg} \cdot \mathrm{m}^{2}\right)$

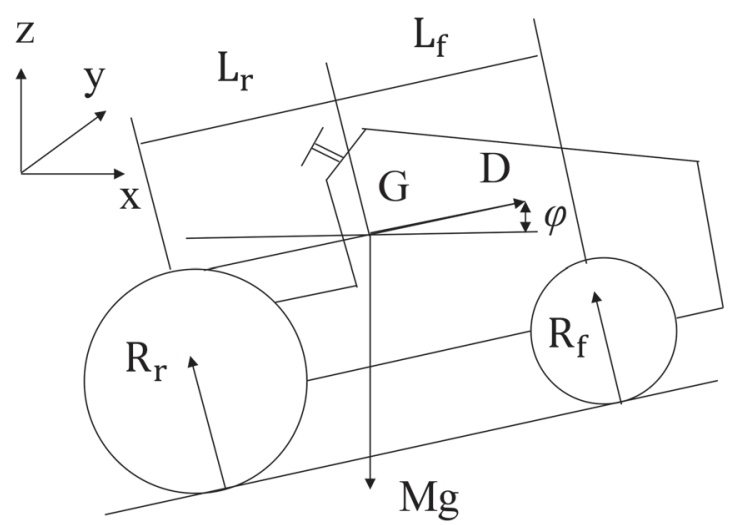

$I_{\mathrm{fx}}$ : The moment of inertia in the front-wheel pivot mechanism's pitching direction $\left(\mathrm{kg} \cdot \mathrm{m}^{2}\right)$

$k$ : $\quad$ Spring constant $(\mathrm{N} / \mathrm{m})$

$c$ : Viscous damping coefficient $(\mathrm{N} \mathrm{s} / \mathrm{m})$

$\ddot{z}, \ddot{\phi}, \ddot{\theta}, \ddot{x}$ in the equation represent the secondorder differentiation of the respective displacements with respect to time, and $\mu R$ and $\gamma R$ indicate traveling resistances. In Equation (7), if reaction force $R$ is 0 or smaller, the tire is considered to be off the road surface, so if $R \leqq 0, R=0$ is entered. One characteristic of the model with a swing mechanism at the front wheels (hereafter the front-wheel pivot model) is that unlike the behavior model for the tractor with a fixed axle (hereafter the fixed support model) (Aoyanagi et al., 2016), the sum of the reaction forces on the left and right front wheel is incorporated to all the equations, so that the moment of inertia from the front-axle swing never influences the machine's rolling.

\section{Simulation}

Based on the above equations of motions, we developed the original program by using MATLAB/Simulink. The program calculated the ground reaction force to the front-rear left-right wheels and performed numerical calculation on respective accelerations of the up-down, pitching and rolling, using the fourth order Runge-Kutta method with $0.01 \mathrm{~s}$ time intervals.

The program diagram in MATLAB/Simulink is shown

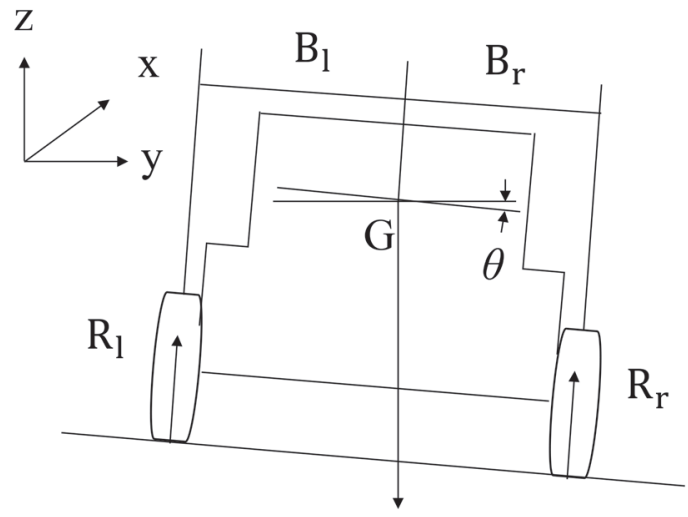

Fig. 1. The model for tractor's behavior.

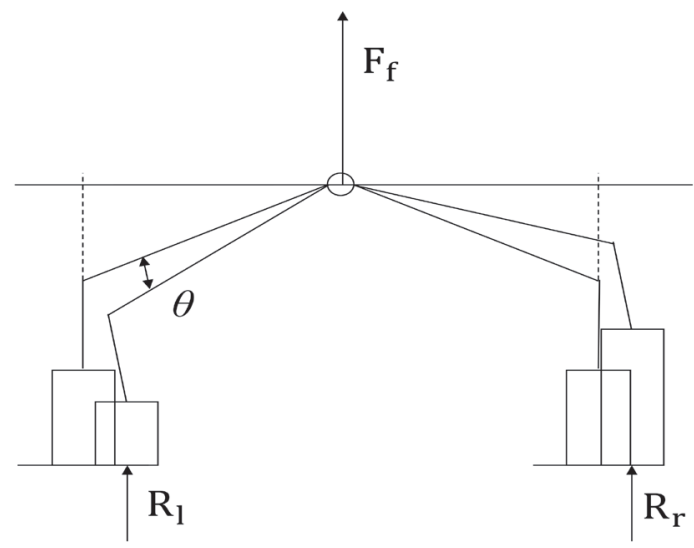

Fig. 2. The model for the front-wheel pivot's behavior. 


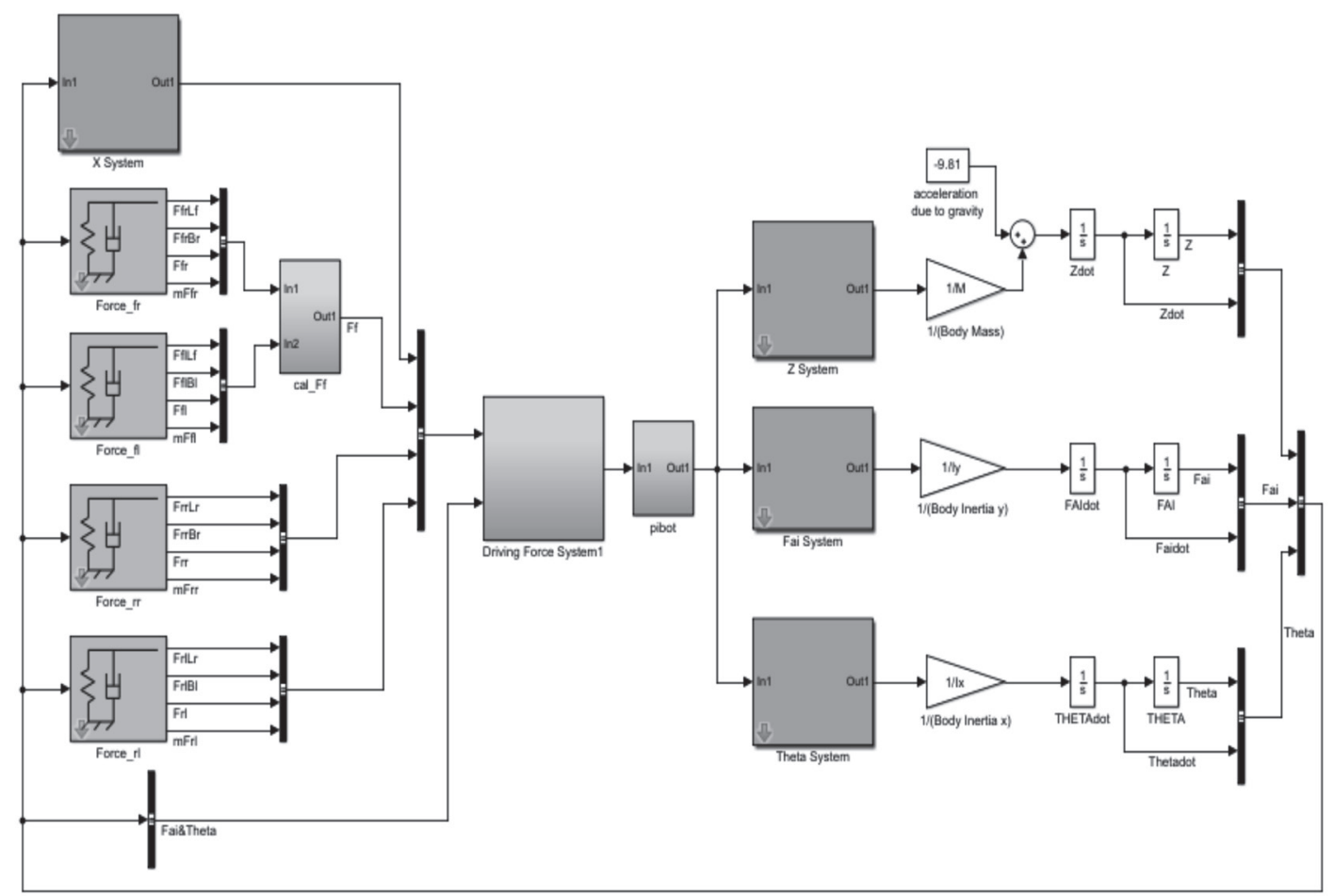

Fig. 3. Program diagram in MATLAB/Simulink.

Table 1. Tractor specifications

\begin{tabular}{lc}
\hline \multicolumn{1}{c}{ Entry } & Value \\
\hline Machine mass (machine + operating tool) (kg) & $1040+75$ \\
Full length(m) & 2.565 \\
Full width (m) & 1.395 \\
Overall height (m) & 1.835 \\
Wheelbase(m) & 1.59 \\
Track Width (m) & 1.115 \\
Horizontal length from machine's center of gravity to & 1.03 \\
front wheels (m) & \\
Vertical length from machine's center of gravity to & 0.96 \\
road surface (m) & 0.63 \\
Front wheel diameter (m) & 1.03 \\
Rear wheel diameter (m) &
\end{tabular}

in Fig. 3. It proceeds with calculating the reaction force to the different wheels on the left, calculating the machine's thrust and the front-wheel pivot mechanism at the center, and solving the respective equations of motions for the up-down, pitching, and rolling motions on the right.

The specifications of the tractor used for the simulation are indicated in Table 1 , and its parameters are indicated in Table 2. The specifications and parameters are taken from those used by Aoyanagi et al. (2016).

\section{RESULTS AND DISCUSSIONS}

We compared and examined the behaviors of the fixed support model and the front-wheel pivot model as they travel on a virtual road surface and reviewed the
Table 2. Parameters

\begin{tabular}{lcc}
\hline \multicolumn{1}{c}{ Description } & Sign & Value \\
\hline Front wheel dynamic spring constant (kN/m) & $k_{\mathrm{f}}$ & 60 \\
Front wheel viscous damping coefficient (Ns/m) & $c_{\mathrm{f}}$ & 200 \\
Rear wheel dynamic spring constant (kN/m) & $k_{\mathrm{r}}$ & 160 \\
Rear wheel viscous damping coefficient (Ns/m) & $c_{\mathrm{r}}$ & 4400 \\
Moment of inertia in the pitching direction $\left(\mathrm{kg} / \mathrm{m}^{2}\right)$ & $I_{\mathrm{y}}$ & 600 \\
Moment of inertia in the rolling direction (kg/m²) & $I_{\mathrm{x}}$ & 203 \\
Distance from center of gravity to right wheel (m) & $B_{\mathrm{r}}$ & 0.56 \\
Distance from center of gravity to left wheel (m) & $B_{\mathrm{l}}$ & 0.56 \\
Distance from center of gravity to front wheel (m) & $L_{\mathrm{f}}$ & 1.03 \\
Distance from center of gravity to rear wheel (m) & $L_{\mathrm{r}}$ & 0.56 \\
Traveling resistance coefficient & $\mu^{2}$ & 0 \\
Height of the center of gravity (m) & $L_{\mathrm{g}}$ & 0.96 \\
Machine mass (kg) & $M$ & 1040 \\
\hline
\end{tabular}

usefulness of each model.

Fig. 4 shows the virtual road surface used in the simulation. The left and right wheels take turns to go over the bumps, and the bumps were configured to be $1.5 \mathrm{~m}$ wide and $0.06 \mathrm{~m}$ high. The machine's traveling distance from the point when the wheel starts climbing the bump to the point when it reaches the crest, and that from the crest to the point when it reaches the bottom were set to be $0.2 \mathrm{~m}$, taking account of the wheel diameter. (1) At $10 \mathrm{~m}$ after traveling from the starting point, the left front wheel starts climbing up the bump, (2) at $11.59 \mathrm{~m}$, which equals the wheelbase, the left rear wheel starts climbing the bump, and (3) at $11.75 \mathrm{~m}$ where the left front wheel finds itself at the bottom, the right front wheel starts 
climbing the bump and the left rear wheel and the right front wheel are at the crest of the bump, simultaneously. Then, (4) at $13.34 \mathrm{~m}$ where the left rear wheel finds itself back at the bottom, the right rear wheel starts climbing up the bump, and (5) at $13.51 \mathrm{~m}$, the right rear wheel alone remains at the crest of the bump. And (6) at $15.09 \mathrm{~m}$, all the wheels have come down from the bump and the machine finds itself level. The driving speed is $1.0 \mathrm{~m} / \mathrm{s}$, and kept at a constant rate during the travel.

The results of the reaction force simulation for the fixed support model are shown in Fig. 5 and Fig. 6, and the results of the reaction force simulation for the frontwheel pivot model are shown in Fig. 7 and Fig. 8.

If we look at the changes to the front-wheel reaction force with the fixed support model in Fig. 5, we can see that at the crossing point (3) where the left front wheel has come down the bump and the right front wheel starts climbing it, the machine is supported mainly by the right front wheel and the left rear wheel so that the reaction force to the left front wheel does not occur. As shown in Fig. 7, we can see that the force which is applied to the front axle in the front-wheel pivot model changes close to a fluctuation according to the machine's motion.

As shown in Fig. 6, the reaction force of the fixed support model works contrariwise to the left and right rear wheels. As the reaction force to the left rear wheel increases, the reaction force to the right rear wheel

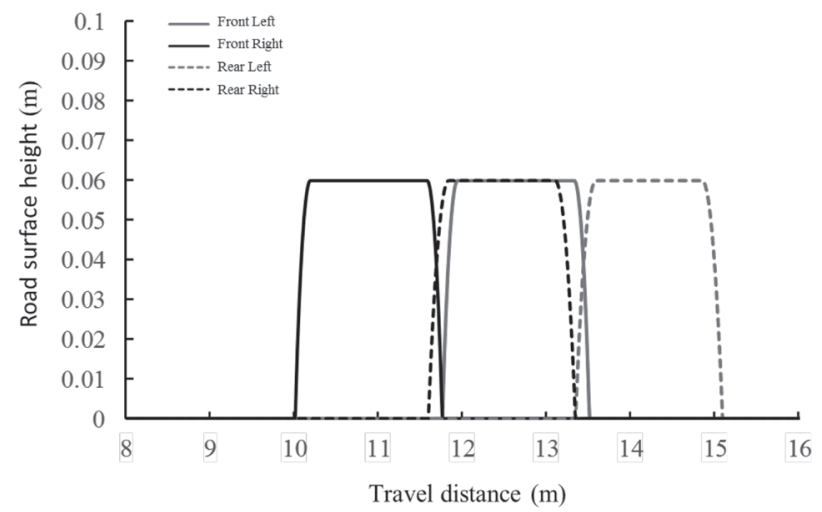

Fig. 4. The terrain data for the test.

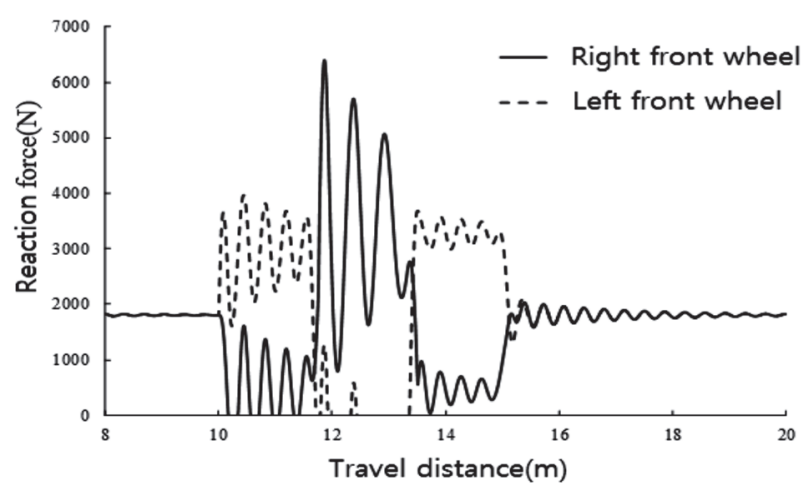

Fig. 5. Reaction force to the left and right front wheels (for the fixed support model). decreases, and as the reaction force to the left rear wheel decreases, the reaction force to the right rear wheel increases, which demonstrated the phenomenon of force transfer. In contrast, the reaction forces to the rear wheels of the front-wheel pivot model, as described in Fig. 8, are shown to be nearly equal for the left and right wheels.

These results show that installing a pivot mechanism on the front wheels brings a huge change not only to the dynamic characteristics of the front axle but also to those of the rear axle.

Fig. 9 and Fig. 10 describe the changes in the rolling angle for the fixed support model and the front-wheel pivot model, respectively. They show that the changes to the rolling angle of the fixed support model are greatly influenced by the 4 -wheel reaction force and the rolling angle fluctuates greatly in the conditions of (2) and (3), so that the machine becomes very unstable. For the front-wheel pivot model, the rolling angle shows no change at (1) when the front wheels climb up the bump but begins to show change when the rear wheels climb up the bump.

\section{CONCLUSION}

In this study, we have developed a behavior simulation program for tractors by using a Runge-Kutta method on the existing fixed support model and front-

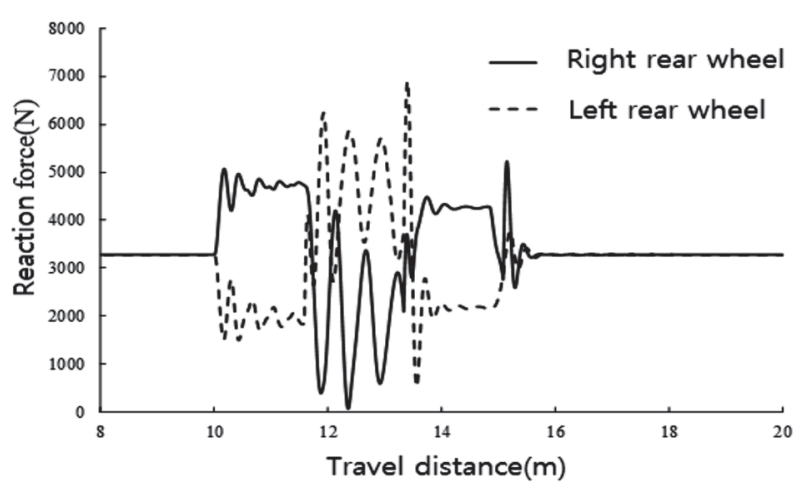

Fig. 6. Reaction force to the left and right rear wheels (for the fixed support model).

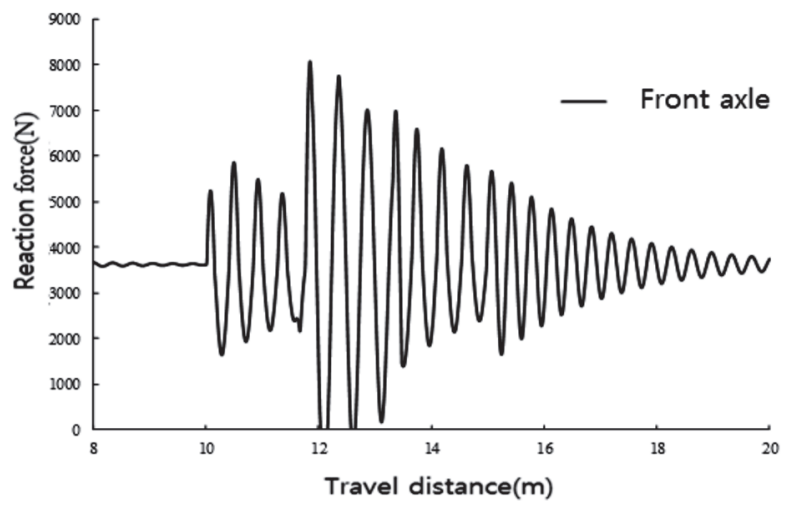

Fig. 7. Reaction force to the front axle (for the front-wheel pivot model). 


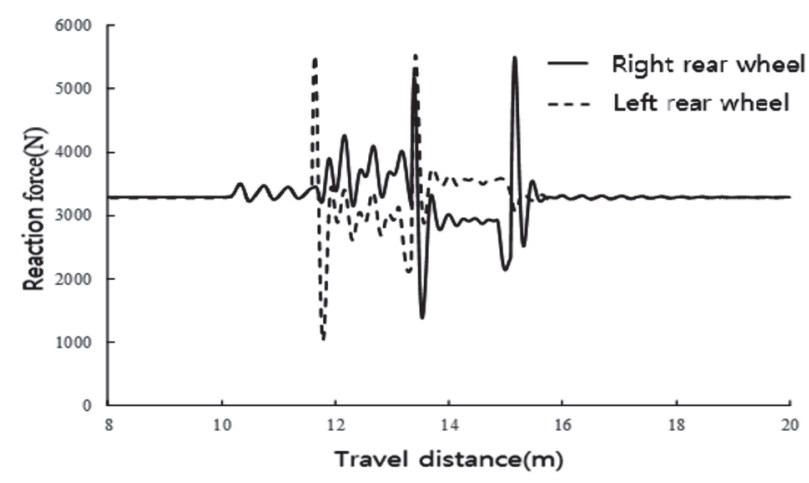

Fig. 8. Reaction force to the left and right rear wheels (for the front-wheel pivot model).

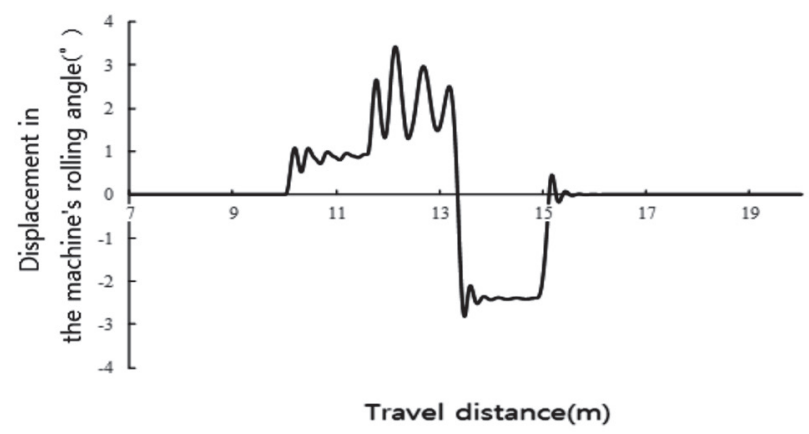

Fig. 9. Displacement in the machine's rolling angle (for the fixed support model).

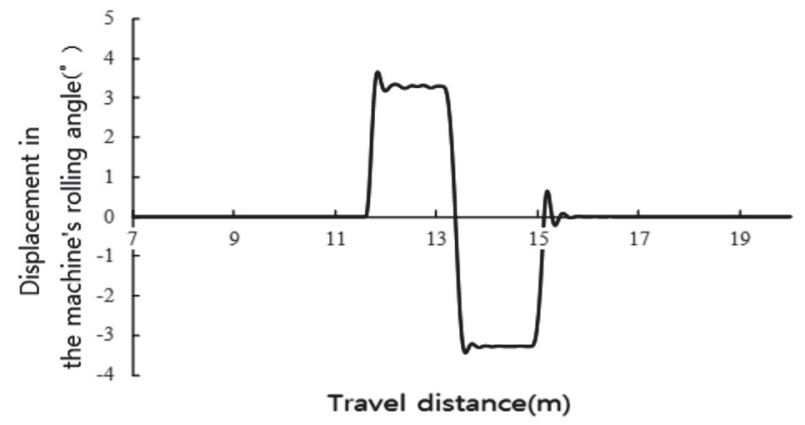

Fig. 10. Displacement in the machine's rolling angle (for the front-wheel pivot model).

wheel pivot model, and through a comparative analysis, we examined the difference between the models and their usefulness. And the summary of the results is as follows.

1. As for front wheel reaction force, the fixed support model showed changes involving left-right symmetry whereas the front-wheel pivot model, as a whole, showed changes in fluctuation according to the motion of the machine.

2. As for rear wheel reaction force, the fixed support model showed changes involving left-right symmetry as with the front wheels whereas it showed in nearly equal levels at both left and right wheels for the front-wheel pivot model, thus verifying that the front-wheel pivot mechanism exercises huge influence not only on the dynamic characteristics of the front axle but also on those of the rear axle.

3. The rolling angle for the fixed support model was greatly influenced by changes in four-wheel reaction force, whereas the front-wheel pivot model did not show any changes when the front wheels were climbing the bump.

Since ordinary tractors have a swing mechanism in the front-wheel axle, the simulation results show that the displacements in the rolling angle of the front axle will not exert any influence on the displacements in the machine's rolling angle when traveling on irregular road surfaces such as the farm roads. Under such circumstances, the front-wheel pivot model should be more appropriate than the fixed support model. However, for farming machines that do not have a pivot mechanism such as rice transplanter, using the fixed axle model could carry out a closer-to-reality simulation.

In future studies, making a comparative analysis between the tractor's dynamic behaviors and the results of this simulation will be able to further establish the usefulness of this simulation program.

\section{AUTHOR CONTRIBUTIONS}

J. Choe designed the study, analyzed the data and wrote the paper. H. Akimune and S. Shine performed the scale model experiments. T. Okayasu and Y. Hirai participated in the design of the study and performed the experiments. E. Inoue and M. Mitsuoka designed the study, supervised the work, wrote the paper and provided facilities and resources. All authors assisted in editing of the manuscript and approved the final version.

\section{ACKNOWLEDGEMENTS}

This Research was supported by Kyungpook National University Research Fund, 2018-2020.

\section{REFERENCES}

Abubakar, M. S., Ahmad, D. and Akande, F. B. 2010 A review of farm tractor overturning accidents and safety. Pertanika Journal of Science and Technology, 18(2): 377-385

Aoyanagi, Y., Matsui, M., Morio, D., Tamura, T., Uchikawa, Y., Kimura, T. 2016 Study on Tractor Behavior Based on Accident Topography. Journal of the Japanese Society of Agricultural Machinery and Food Engineers 78(6): 529-535

Guzzomi, A. L. 2012 A revised kineto-static model for Phase I tractor rollover. Biosystems Eng., 113(1): 65-75

Homori, H., Sakai, K., Sasao, A. and Sibusawa, S. 2003 2D dynamics simulator for impact oscillators analysis of tractor-implement system. Journal of the Japanese Society of Agricultural Machinery, $\mathbf{6 5}(1)$ : 85-90

Li, Z., Mitsuoka, M., Inoue, E., Okayasu, T. and Hirai, Y. 2015 Development of stability indicators for dynamic Phase I overturn of conventional farm tractors with front axle pivot. Biosysems Engineering., 134: 55-67

Yoshida, Y. 2012 Solution of an Equation of Motion using MATLAB/Simulink. Technical reports of Tottori Institute of Industrial Technology 15: 40-43 